L. B. Gerson J. Van Dam

\title{
A Prospective Randomized Trial Comparing a Virtual Reality Simulator to Bedside Teaching for Training in Sigmoidoscopy
}

Gerson LB, Van Dam J. A prospective randomized trial comparing a virtual reality simulator to bedside teaching for training in sigmoidoscopy. Endoscopy 2003; 35: 569- 575

Reference number 7: Aabakken L, Adamsen S, Kruse A. Performance of a colonoscopy simulator: experience from a hands-on endoscopy course. Endoscopy 2000; 32: $911-913$ is incorrect and should be as follows:

Ferlitsch A, Glauninger P, Gupper A et al. Evaluation of a virtual endoscopy simulator for training in gastrointestinal endoscopy. Endoscopy 2002; 34: 698 - 702 